\title{
Impact of telephonic interviews on persistence and daily adherence to insulin treatment in insulin-naïe type 2 diabetes patients: dropout study
}

This article was published in the following Dove Press journal:

Patient Preference and Adherence

17 May 2016

Number of times this article has been viewed

Dilek Gogas Yavuz,' Habip Bilen, ${ }^{2}$ Seda Sancak, ${ }^{3}$ Tayfun Garip, ${ }^{4}$

Zeliha Hekimsoy, ${ }^{5}$ Ibrahim Sahin, ${ }^{6}$ Murat Yilmaz, ${ }^{7}$ Hasan Aydin, ${ }^{8}$ Aysegul Atmaca, ${ }^{9}$ Murat Sert, ${ }^{10}$ Pinar Karakaya, "' Dilek Arpaci, ${ }^{4}$ Aytekin Oguz, ${ }^{12}$ Nilgun Guvener ${ }^{13}$

On behalf of the Dropout Study Group

'Department of Endocrinology and Metabolism, Marmara University Faculty of Medicine, Istanbul, ${ }^{2}$ Department of Endocrinology and Metabolism, Ataturk University Faculty of Medicine, Erzurum, ${ }^{3} \mathrm{Clinic}$ of Endocrinology and Metabolism, Fatih Sultan Mehmet Training and Research Hospital, Istanbul, ${ }^{4} \mathrm{Clinic}$ of Endocrinology and Metabolism, Sakarya State Hospital, Sakarya, ${ }^{5}$ Department of Endocrinology and Metabolism, Celal Bayar University Faculty of Medicine, Manisa, ${ }^{6}$ Department of Endocrinology and Metabolism, Inonu University Faculty of Medicine, Malatya, ${ }^{7}$ Department of Endocrinology and Metabolism, Namık Kemal University Faculty of Medicine, Tekirdag, ${ }^{8}$ Department of Endocrinology and Metabolism, Yeditepe University Faculty of Medicine, Istanbul, 'Department of Endocrinology and Metabolism, Ondokuzmayıs University Faculty of Medicine, Samsun, ${ }^{10}$ Department of Endocrinology and Metabolism, Cukurova University Faculty of Medicine, Adana, "Clinic of Endocrinology and Metabolism, Bakırkoy Training and Research Hospital, Istanbul, ${ }^{12}$ Department of Internal Medicine, Medeniyet University Faculty of Medicine, Istanbul, ${ }^{13}$ Department of Endocrinology and Metabolism, Baskent University Faculty of Medicine, Istanbul, Turkey

Correspondence: Dilek Gogas Yavuz Department of Endocrinology and Metabolism, Faculty of Medicine, Marmara University, Fevzi Cakmak Mahallesi, Muhsin Yazicioglu Caddesi, No I0, Ust Kaynarca, Pendik, 34584 Istanbul, Turkey

Tel/fax +902166254685

Email dilekgogas@marmara.edu.tr
Objective: The objective of this study is to evaluate the impact of sequential telephonic interviews on treatment persistence and daily adherence to insulin injections among insulin-naïve type 2 diabetes patients initiated on different insulin regimens in a 3-month period.

Methods: A total of 1,456 insulin-naïve patients with type 2 diabetes (mean [standard deviation, SD] age: 56.0 [12.0] years, $49.1 \%$ were females) initiated on insulin therapy and consecutively randomized to sequential $(n=733)$ and single $(n=723)$ telephonic interview groups were included. Data on insulin treatment and self-reported blood glucose values were obtained via telephone interview. Logistic regression analysis was performed for factors predicting increased likelihood of persistence and skipping an injection.

Results: Overall, $76.8 \%$ patients $(83.2 \%$ in sequential vs $70.3 \%$ in single interview group, $(P<0.001)$ remained on insulin treatment at the third month. Significantly higher rate for skipping doses was noted in basal bolus than in other regimens $(27.0 \%$ vs $15.0 \%$ for premixed and $15.8 \%$ basal insulin, respectively, $P<0.0001$ ). Logistic regression analysis revealed sequential telephonic interview (odds ratio [OR], 1.531; 95\% confidence interval [CI], 1.093-2.143; $P=0.013$ ), higher hemoglobin A1c levels (OR, 1.090; 95\% CI, 0.999-1.189; $P=0.049$ ), and less negative appraisal of insulin therapy as significant predictors of higher persistence. Basal bolus regimen $(\mathrm{OR}, 1.583 ; 95 \%$ CI, 1.011-2.479; $P=0.045)$ and higher hemoglobin A1c levels (OR, 1.114; 95\% CI, 1.028-1.207; $P=0.008)$ were the significant predictors of increased likelihood of skipping an injection.

Conclusion: Our findings revealed positive influence of sequential telephonic interview, although including no intervention in treatment, on achieving better treatment persistence in type 2 diabetes patients initiating insulin.

Keywords: type 2 diabetes, insulin analogs, HbA1c, self-monitoring of blood glucose

\section{Introduction}

Barriers toward insulin therapy have been associated with easily avoidable challenges related to clinicians, patients, and health-care system in diabetes management. ${ }^{1,2}$ However, insulin omission/nonadherence and the consequent prolonged periods of poor glycemic control have been closely linked to negative clinical outcomes, including increased severity and progression of diabetic complications. ${ }^{3-6}$

Although data from the multinational The Global Attitudes of Patients and Physicians in Insulin Therapy (GAPP) survey revealed that insulin omission/nonadherence was reported to be highest in Turkey, followed by the USA, the People's Republic of China, and Japan, and lowest in France, Germany, UK, and Spain, ${ }^{4,7}$ no countryspecific data are available in Turkey considering the adherence to insulin therapy and reasons for treatment withdrawal in insulin-naïve type 2 diabetes patients. 
This multicenter study was designed to evaluate the impact of single vs sequential telephonic interviews on shortterm adherence to insulin treatment in insulin-naïve type 2 diabetes patients initiated on different insulin regimens.

\section{Methods}

\section{Study population}

A total of 1,456 insulin-naïve patients with type 2 diabetes (mean [standard deviation (SD)] age: 56.0 [12.0] years, 49.1\% were females) initiated on insulin therapy were recruited from 13 tertiary care centers across Turkey in this 12-week open-label randomized multicenter study conducted between October 2012 and April 2013. All type 2 diabetes outpatients who were referred to a diabetes education nurse to be trained on insulin treatment were included in the study, provided that they were aged 18-70 years, diagnosed with type 2 diabetes for at least 1 year, and were insulin naïve. Patients with type 1 diabetes, gestational diabetes, ongoing insulin treatment, or insulin use within the last 3 months were excluded from the study. All patients were initiated on insulin pen therapy and trained on insulin treatment and use of insulin pen by the same registered nurse. A total of five patients with treatment switching were not subjected to subgroup analyses.

Written informed consent was obtained from each subject following a detailed explanation of the objectives and protocol of the study, which was conducted in accordance with the ethical principles stated in the Declaration of Helsinki and approved by the Marmara University Faculty of Medicine's Ethics Committee.

\section{Data collection}

Baseline enrollment visit (day 0) was performed at the time of insulin initiation during insulin education in all patients who met the inclusion criteria. Afterward, patients were consecutively randomized to sequential $(n=733$, four repeated follow-up interviews on day 15 , day 30 , day 60 , and day 90 ) and single ( $\mathrm{n}=723$, single follow-up interview at day 90$)$ telephonic interview groups, depending on the schedule of phone interviews given during a 3-month follow-up.

Data on patient demographics (age and sex), educational status, and concerns about insulin treatment (efficacy in blood glucose lowering and risk of weight gain, hypoglycemia, painful injection, and becoming insulin dependent) were recorded at baseline enrollment visit via face-to-face interviewing.

Data on anthropometrics, diabetes history, comorbid disorders, antidiabetic and concomitant medications, initiated insulin regimen (type [basal bolus, premixed, and basal insulin], insulin pen needle size, and dosage schedule [morning, noon, evening, and nighttime]), and glycemic parameters (fasting blood glucose [FBG, mg/dL], postprandial blood glucose [PPBG, mg/dL], and hemoglobin A1c $[\mathrm{HbA} 1 \mathrm{c} ; \%, \mathrm{mmol} / \mathrm{mol}]$ ) values within the last 3 months were collected based on medical records.

During phone interviews, data on adherence to insulin treatment, insulin administration practice (self-injection or not), problems related to injection administration (discomfort/pain/itching at injection site), and blood glucose values measured within the last 15 days were recorded for all patients with no interference in insulin treatment. Routine follow-up of all patients was performed by their physicians who initiated the insulin regimen. Mean values for FBG and PPBG were calculated based on self-reported measurements in the past 15 days, as were $\mathrm{HbAlc}$ values. The reasons for treatment withdrawal (problems related to injection administration [discomfort/pain/itching at injection site], hypoglycemic events, normalization of blood glucose levels, at physicians' discretion, influence of family members and friends, workload/workplace conditions, weight gain, challenges in drug procurement, and allergic side effects) were recorded for discontinuers, while type and dosage of ongoing insulin treatment, dose adjustments, hypoglycemic events, skipping an injection for at least once in the last 15 days, the number of skipped doses, and most commonly skipped dose (morning/noon/evening/nighttime) in the last 15 days were recorded for continuers.

\section{Study parameters}

Baseline demographic and clinical characteristics, baseline and third month glycemic, anthropometric, and treatmentrelated characteristics and insulin doses, third month rates for treatment adherence and skipping doses, and reported hypoglycemia frequency were evaluated with respect to interview groups and insulin regimen. Third month glycemic and anthropometric parameters were also evaluated according to skipping doses in continuers, while reasons for treatment discontinuation were identified in discontinuers. Patients' view on insulin therapy before and after treatment initiation was recorded. Logistic regression analysis was performed for factors predicting higher persistence and increased likelihood of skipping an injection.

\section{Statistical analysis}

Statistical analysis was made using computer software (GraphPad InStat 3.0; GraphPad Software, Inc., San Diego, CA, USA). Chi-square $\left(\chi^{2}\right)$ test was used for the comparison 
of categorical data, while Student's $t$-test and analysis of variance were used for the parametric variables. Logistic regression analysis was performed with persistence and skipping doses (categorical) as the dependent variables, while "Enter" was selected as the method and "simple first" as the categorical variable coding scheme. Predictors with possible influence on dependent variable were added as covariates. Data were expressed as "mean (SD)", minimum-maximum, percent (\%), odds ratio (OR), and 95\% confidence interval ( $\mathrm{CI}$, $\min -\max$ ), where appropriate. $P<0.05$ was considered statistically significant.

\section{Results}

\section{Baseline demographic and clinical characteristics}

Of 1,456 patients subjected to "follow-up based" analyses, $733(50.3 \%)$ were in the sequential and $723(49.7 \%)$ were in the single telephonic interview groups. Of 1,451 patients subjected to "insulin regimen-based" analyses, 399 (27.5\%) received basal bolus regimen, 604 (41.6\%) received premixed regimen, and $448(30.9 \%)$ received basal insulin according to doctor's orders.

No significant difference was noted in demographic and clinical characteristics as well as selected insulin regimen in patients with respect to type of follow-up. Patients initiating basal bolus regimen were aged younger (mean [SD] 55.0 [12.4] years) than patients initiating premixed (57.1 [11.0] years, $P<0.05)$ or basal insulin (58.1 [12.2] years, $P<0.01$ ) regimens (Table 1 ).

\section{Treatment adherence}

Overall 1,114 (76.8\%) patients remained on insulin treatment at the third month of study, treatment withdrawal occurred in $225(15.5 \%)$ patients and $112(7.7 \%)$ patients could not be accessed (Table 2).

In the sequential interview group, persistence rates were $94.1 \%$ on day $15,90.0 \%$ on day 30 , and $89.2 \%$ on day 60. Sequential rather than single telephonic interview was associated with significantly higher persistence $(83.2 \%$ vs $70.3 \%, P<0.001)$ and less inability to access patients $(2.9 \%$ vs $12.6 \%, P<0.001)$. No significant difference was noted in persistence rates with respect to insulin regimen $(76.9 \%$ in basal bolus, $78.6 \%$ in premixed, and $74.1 \%$ in basal insulin groups) (Table 2).

Basal bolus $(83.0 \%$ vs $69.3 \%, P<0.0001)$ and basal insulin ( $84.8 \%$ vs $62.8 \%, P<0.0001)$ regimens were associated with higher persistence rates in the case of sequential rather than single telephonic interview, while persistence rates were similarly high in sequential $(81.9 \%)$ and single (75.8\%) interview groups receiving premixed insulin regimen. In the sequential interview group, similar persistence rates were noted with respect to different insulin regimens, whereas in the single interview group, higher persistence was noted in patients receiving premixed regimen $(75.8 \%)$ than in basal insulin $(62.8 \%)$ regimen $(P<0.05)$ (Table 2$)$.

\section{Reasons for treatment withdrawal}

Accordingly, treatment withdrawal was identified to be mostly at the patient's discretion $(57.3 \%, \mathrm{n}=71)$, followed

Table I Baseline demographic and clinical characteristics with respect to follow-up type and insulin regimen

\begin{tabular}{|c|c|c|c|c|c|c|c|}
\hline & \multicolumn{3}{|c|}{ Telephonic interview } & \multicolumn{4}{|c|}{ Insulin regimen } \\
\hline & $\begin{array}{l}\text { Sequential } \\
(n=733)\end{array}$ & $\begin{array}{l}\text { Single } \\
(n=723)\end{array}$ & $P$-value & $\begin{array}{l}\text { Basal bolus } \\
(n=399)\end{array}$ & $\begin{array}{l}\text { Premixed } \\
(n=604)\end{array}$ & $\begin{array}{l}\text { Basal insulin } \\
(n=448)\end{array}$ & P-value \\
\hline Age (year), mean (SD) & $56.4(12.2)$ & $57.4(1 \mathrm{I} .8)$ & $\left.0.13\right|^{\mathrm{a}}$ & $55.0(12.4)^{*}$ & $57.1(1 \mathrm{I} .0) * *$ & $58.1(12.2)$ & $0.002^{b}$ \\
\hline \multicolumn{8}{|l|}{ Sex, n (\%) } \\
\hline Female & 350 (47.9) & $364(50.3)$ & $0.347^{c}$ & $156(46.4)$ & $226(48.6)$ & $157(49.1)$ & 0.763 \\
\hline Male & $381(52.1)$ & $359(49.7)$ & & $180(53.6)$ & $239(5 \mathrm{I} .4)$ & $163(50.9)$ & \\
\hline Diabetes duration (year), mean (SD) & $6.0(6.5)$ & $6.6(6.2)$ & $0.112^{\mathrm{a}}$ & $6.2(5.7)$ & $6.9(6.0)$ & $7.0(5.8)$ & 0.140 \\
\hline Illiteracy, n (\%) & $102(14.0)$ & $127(17.6)$ & $0.746^{c}$ & $5 \mathrm{I}(15.4)$ & $63(13.5)$ & $43(13.5)$ & 0.721 \\
\hline \multicolumn{8}{|l|}{ Comorbidities, n (\%) } \\
\hline Hypertension & $350(47.4)$ & $351(48.5)$ & $0.710^{c}$ & $199(49.8)$ & $288(47.6)$ & $214(47.7)$ & 0.066 \\
\hline Hyperlipidemia & $385(52.5)$ & $402(55.6)$ & $0.412^{c}$ & $225(56.3)$ & $312(53.4)$ & $250(55.8)$ & 0.412 \\
\hline Proved coronary artery disease & $120(16.3)$ & $106(14.6)$ & $0.8 I^{c}$ & $68(17.7)$ & $81(13.7)$ & $77(17.6)$ & 0.831 \\
\hline \multicolumn{8}{|l|}{ Insulin regimen, n (\%) } \\
\hline Basal bolus $(n=399)$ & $223(55.9)$ & $176(44.1)$ & $0.057^{c}$ & & & & \\
\hline Premixed $(n=604)$ & 277 (45.9) & $327(54.1)$ & $0.06^{c}$ & & & & \\
\hline Basal insulin $(n=448)$ & $230(5 \mathrm{I} .3)$ & 218 (48.7) & $0.356^{c}$ & & & & \\
\hline Total $(n=I, 45 I)^{d}$ & $730(50.3)$ & 721 (49.7) & $0.87^{c}$ & & & & \\
\hline
\end{tabular}

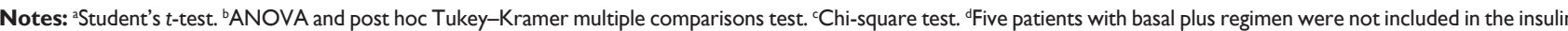
regimen based analyses. $* P<0.01$ compared to basal insulin regimen. ${ }^{* *} P<0.05$ compared to basal insulin regimen. Values in bold indicate statistical significance $(P<0.05)$. Abbreviations: SD, standard deviation; ANOVA, Analysis of variance. 
Table 2 Treatment adherence at third month with respect to follow-up type and insulin regimen

\begin{tabular}{|c|c|c|c|c|}
\hline & \multicolumn{4}{|c|}{ Third month treatment adherence } \\
\hline & Persistence & $\begin{array}{l}\text { Treatment } \\
\text { withdrawal }\end{array}$ & $\begin{array}{l}\text { Inability to access } \\
\text { patient }\end{array}$ & Total \\
\hline \multicolumn{5}{|l|}{ Interview type } \\
\hline Sequential & $607(83.2)$ & $102(14.0)$ & $21(2.9)$ & $730(100.0)$ \\
\hline Single & $507(70.3)$ & $123(17.1)$ & $91(12.6)$ & $721(100.0)$ \\
\hline Total & $\mathrm{I}, \mathrm{I} / 4(76.8)$ & $225(15.5)$ & $112(7.7)$ & $|, 45|(100.0)$ \\
\hline$P$-value & $<0.0001$ & & & \\
\hline \multicolumn{5}{|l|}{ Insulin regimen } \\
\hline Basal bolus & $307(76.9)$ & $62(15.5)$ & $30(7.5)$ & $399(100.0)$ \\
\hline Premixed & $475(78.6)$ & $83(13.7)$ & $46(7.6)$ & $604(100.0)$ \\
\hline Basal insulin & $332(74.1)$ & $80(17.9)$ & $36(8.0)$ & $448(100.0)$ \\
\hline$P$-value & 0.45 & & & \\
\hline \multicolumn{5}{|l|}{ Basal bolus } \\
\hline Sequential interview & $185(83.0)$ & $31(13.9)$ & $7(3.1)$ & $223(100.0)$ \\
\hline Single interview & $122(69.3)^{*}$ & $31(17.6)$ & $23(13.1)$ & $176(100.0)$ \\
\hline \multicolumn{5}{|l|}{ Premixed } \\
\hline Sequential interview & $227(81.9)$ & $39(14.1)$ & II (4.0) & $277(100.0)$ \\
\hline Single interview & $248(75.8)^{* *}$ & $44(13.5)^{* *}$ & $35(10.7)$ & $327(100.0)$ \\
\hline \multicolumn{5}{|l|}{ Basal insulin } \\
\hline Sequential interview & I $95(84.8)$ & 32 (13.9) & $3(1.3)$ & $230(100.0)$ \\
\hline Single interview & $137(62.8)^{*}$ & $48(22.0)$ & $33(15.1)$ & $218(100.0)$ \\
\hline
\end{tabular}

Notes: Data are expressed as $n(\%)$. Chi-square test. $* P<0.0001$ compared to patients with sequential interview in the same regimen. $* * P<0.05$ compared to single interview in the basal insulin regimen.

by being at physicians' discretion $(25.0 \%, \mathrm{n}=31)$. Drug side effects $(4.8 \%, \mathrm{n}=6)$, influence of patient's family/environment $(0.8 \%, \mathrm{n}=1)$, problems related to drug procurement $(0.8 \%, \mathrm{n}=1)$ or health-care system $(0.8 \%, \mathrm{n}=1)$ were the other reasons for treatment withdrawal, while death occurred in 13 patients $(10.5 \%)$. Reasons for patients to decide to discontinue treatment were normalization of blood glucose (30.6\%), influence of family members and friends (10.5\%), allergic side effects $(4.8 \%)$, problems related to workload/workplace environment (6.4\%), and drug procurement (4.0\%).

\section{Skipping doses}

Overall 186 out of 878 patients (21.2\%) at the third month identified that they skipped doses with no significant difference between sequential and single interview groups ( $21.4 \%$ and $21.9 \%$, respectively, $P=0.830$ ), whereas there was a significantly higher rate for skipping doses in basal bolus than in premixed and basal insulin regimens $(27.0 \%$ vs $15.0 \%$ and $15.8 \%$, respectively, $P<0.0001)$. Among 154 patients with available data, noon and evening doses $(23.1 \%$ for each) were the most commonly skipped doses, followed by morning dose (18.8\%), nighttime dose (13.4\%), and all doses $(4.3 \%)$. At the end of the third month, significantly higher mean (SD) values for FBG (157.2 [57.9] mg/dL vs 143.6 [48.8] $\mathrm{mg} / \mathrm{dL}, P=0.013$ ) were noted among patients with, than without, skipping doses, while the two groups were similar in terms of PPBG (mean [SD] 199.7 (85.7) $\mathrm{mg} / \mathrm{dL}$ vs $198.4[75.6] \mathrm{mg} / \mathrm{dL}, P=0.897$ ) and HbA1c (mean [SD] 8.5\%
[1.8\%] (69 [20] mmol/mol) vs $8.1 \%$ [1.5\%] (65 [16] mmol/ mol), $P=0.096])$.

\section{Insulin doses}

No significant change was noted in insulin doses at baseline and third month in sequential vs single interview groups (Table 3).

Among the three types of insulin regimens, basal insulin was associated with the lowest total daily insulin dose both at baseline (14.7 [6.5] IU/d vs 43.8 [21.4] IU/d for basal bolus and 30.3 [13.8] IU/d for premixed, $P<0.001$ for each) and at the third month $(21.7$ [12.3] IU/d vs 46.0 [20.8] IU/d for basal bolus and 37.4 [15.8] IU/d for premixed, $P<0.001$ for each), as well as with the lowest insulin per $\mathrm{kg}$ doses at the baseline $(0.2$ [0.1] IU/kg vs 0.6 [0.3] IU $/ \mathrm{kg}$ for basal bolus and 0.4 [0.2] IU $/ \mathrm{kg}$ for premixed, $P<0.001$ for each), while the three regimens had similar insulin per $\mathrm{kg}$ doses at the third month (Table 3).

Except for significantly higher third month total daily insulin doses in sequential than in single interview group of patients initiating basal insulin (23.0 [12.8] vs 20.1 [11.5] IU/d, $P=0.033$ ) and significantly higher per $\mathrm{kg}$ insulin doses in single than in sequential interview group of patients initiating premixed insulin $(0.44[0.3] \mathrm{IU} / \mathrm{kg}$ vs 0.38 $[0.2] \mathrm{IU} / \mathrm{kg}, P=0.004)$, baseline and third month total daily and per $\mathrm{kg}$ insulin doses were similar between sequential and single interview group of patients initiating basal bolus, premixed, and basal insulin regimens (Table 3). 
Table 3 Baseline and third month total daily and per $\mathrm{kg}$ insulin doses

\begin{tabular}{|c|c|c|c|c|c|c|c|c|c|c|c|c|}
\hline & \multicolumn{6}{|c|}{ Total daily dose (IU/d) } & \multicolumn{6}{|c|}{ Dose/kg (IU/kg) } \\
\hline & \multicolumn{3}{|c|}{ Baseline } & \multirow{2}{*}{\multicolumn{3}{|c|}{$\begin{array}{l}\text { Third month, } \\
\text { mean (SD) }\end{array}$}} & \multirow{2}{*}{\multicolumn{3}{|c|}{$\begin{array}{l}\text { Baseline, } \\
\text { mean (SD) }\end{array}$}} & \multirow{2}{*}{\multicolumn{3}{|c|}{$\begin{array}{l}\text { Third month, } \\
\text { mean (SD) }\end{array}$}} \\
\hline & $\mathbf{n}$ & Mean (SD) & & & & & & & & & & \\
\hline \multirow{3}{*}{$\begin{array}{l}\text { All patients } \\
P \text {-value }\end{array}$} & $\mathrm{I}, 456$ & $29.4(17.9)$ & & \multirow{2}{*}{\multicolumn{3}{|c|}{$34.8(18.8)$}} & \multirow{2}{*}{\multicolumn{3}{|c|}{$\begin{array}{l}0.4(0.3 \\
0.949\end{array}$}} & \multirow{2}{*}{\multicolumn{3}{|c|}{$0.4(0.3)$}} \\
\hline & \multicolumn{3}{|c|}{$<\mathbf{0 . 0 0 0 I}$} & & & & & & & & & \\
\hline & $\mathbf{n}$ & Mean (SD) & $P$-value ${ }^{a}$ & $\mathbf{n}$ & Mean (SD) & $P$-value ${ }^{a}$ & $\mathbf{n}$ & Mean (SD) & $P$-value ${ }^{a}$ & $\mathbf{n}$ & Mean (SD) & $P$-value ${ }^{a}$ \\
\hline \multicolumn{13}{|l|}{ Telephonic interview } \\
\hline Sequential interview & 733 & $29.6(18.3)$ & 0.359 & 528 & $35.3(18.8)$ & 0.320 & 721 & $0.4(0.2)$ & 0.569 & 723 & $0.4(0.2)$ & 0.076 \\
\hline Single interview & 723 & $28.7(18.7)$ & & 486 & $34.1(18.9)$ & & 707 & $0.4(0.3)$ & & 712 & $0.4(0.3)$ & \\
\hline \multicolumn{13}{|l|}{ Insulin regimen } \\
\hline Basal bolus & 399 & $43.8(21.4)^{* *}$ & $<0.00 \mathrm{I}^{\mathrm{b}}$ & 264 & $46.0(20.8)^{* *}$ & $<0.00 \mathrm{I}^{\mathrm{b}}$ & 391 & $0.6(0.3)^{* *}$ & $<0.00 \mathrm{I}^{\mathrm{b}}$ & 394 & $0.4(0.3)$ & 0.119 \\
\hline Premixed & 604 & $30.3(13.8)^{*}$ & & 435 & $37.4(15.8)^{*}$ & & 599 & $0.4(0.2)^{*}$ & & 599 & $0.4(0.3)$ & \\
\hline Basal insulin & 448 & $14.7(6.5)$ & & 315 & $21.7(12.3)$ & & 438 & $0.2(0.1)$ & & 442 & $0.4(0.2)$ & \\
\hline \multicolumn{13}{|l|}{ Basal bolus } \\
\hline Sequential interview & 220 & $44.2(20.0)$ & 0.6 & 149 & $46.2(19.5)$ & 0.846 & 220 & $0.58(0.25)$ & 0.693 & 220 & $0.4(0.2)$ & 0.517 \\
\hline Single interview & 171 & $43.2(22.0)$ & & 115 & $45.7(22.3)$ & & $17 \mid$ & $0.57(0.3 \mathrm{I})$ & & 174 & $0.4(0.3)$ & \\
\hline \multicolumn{13}{|l|}{ Premixed } \\
\hline Sequential interview & 278 & $29.8(13.1)$ & 0.45 & 201 & $38.1(16.5)$ & 0.349 & 278 & $0.42(0.17)$ & 0.58 & 276 & $0.38(0.2)$ & 0.004 \\
\hline Single interview & 323 & $31.3(14.0)$ & & 234 & $36.7(15.2)$ & & 323 & $0.44(0.21)$ & & 323 & $0.44(0.3)$ & \\
\hline \multicolumn{13}{|l|}{ Basal insulin } \\
\hline Sequential interview & 225 & I5.2(7.3) & 0.56 & 178 & $23.0(12.8)$ & 0.033 & 225 & $0.20(0.09)$ & 0.34 & 227 & $0.4(0.2)$ & 0.942 \\
\hline Single interview & 213 & |4.| (5.5) & & 137 & $20.1(11.5)$ & & 213 & $0.19(0.07)$ & & 215 & $0.4(0.2)$ & \\
\hline
\end{tabular}

Notes: ${ }^{2}$ Student's $t$-test. ${ }^{b}$ ANOVA and post hoc Tukey-Kramer multiple comparisons test. $* P<0.001$ compared to basal insulin regimen. $* * p<0.001$ compared to basal insulin and premixed regimens. Values in bold indicate statistical significance $(P<0.05)$.

Abbreviations: SD, standard deviation; ANOVA, Analysis of variance.

\section{Glycemic parameters}

No significant difference was noted in either baseline or third month anthropometric and glycemic parameters between sequential and single interview groups. From baseline to third month, HbAlc decreased from $10.5 \%$ (2.2\%) to $8.2 \%$ $(1.6 \%)$ and from $10.4 \%(2.1 \%)$ to $8.2 \%(1.6 \%)$ in sequential and single interview groups, respectively (Table 4).

Among the three insulin regimens, basal insulin was associated with lowest mean (SD) baseline FBG (209.5 [62.0] $\mathrm{mg} / \mathrm{dL}$ vs 257.5 [78.0] mg/dL for basal bolus and 228.5 [83.0] mg/dL for premixed, $P<0.001$ for each) and baseline HbA1c $(9.7 \%$ [2.0\%] vs $11.3 \%$ [2.3\%] for basal bolus and $10.5 \%$ [2.0\%] for premixed, $P<0.001$ for each) levels, while the three regimens had similar third month HbAlc levels (Table 4).

No significant difference was noted in anthropometrics at baseline and third month of study with respect to type of interview or insulin regimen (Table 4).

\section{Hypoglycemia}

Reported minor and major hypoglycemia was determined in 264 of 1,017 (26.0\%) patients, similarly in sequential (23.6\%) and single (28.4\%) interview groups. Basal insulin regimen was associated with significantly lower rate of hypoglycemia $(11.2 \%, P<0.0001)$ as compared with basal bolus (30.5\%) and premixed $(24.0 \%)$ regimens, particularly in the case of single interview ( $8.5 \%$ vs $32.5 \%$ and $38.6 \%$, respectively, $P<0.001$ ) (Table 5).

\section{Patients' view on insulin therapy}

Before insulin treatment initiation, $47.8 \%$ of patients considered insulin treatment positively, while negative beliefs were identified in $29.1 \%$ of patients before treatment. Major concerns about the insulin treatment were about the painful injections (36.7\%), risk of becoming insulin dependent $(32.4 \%)$, risk of hypoglycemia $(25.0 \%)$, and weight gain $(22.1 \%)$, while $85.1 \%$ of patients considered insulin to be an effective agent in blood glucose lowering (Table 6).

At the third month of insulin treatment, self-injection with insulin pen was identified by $56.2 \%$ of patients, which was considered to be a painless procedure by $59.1 \%$ and identified to be associated with itching (2.2\%) or hives/swelling (1.2\%) at the injection site by a few patients (Table 6).

\section{Factors predicting treatment persistence and skipping an injection}

Logistic regression analysis with persistence as the dependent variable revealed that longer diabetes duration (OR, $1.063 ; 95 \%$ CI, $1.026-1.102 ; P=0.001)$, sequential telephonic interview (OR, 1.531; 95\% CI, 1.093-2.143; $P=0.013$ ), and higher HbA1c levels (OR, 1.090; 95\% CI, 0.999-1.189; $P=0.049)$ were associated with increased likelihood of 


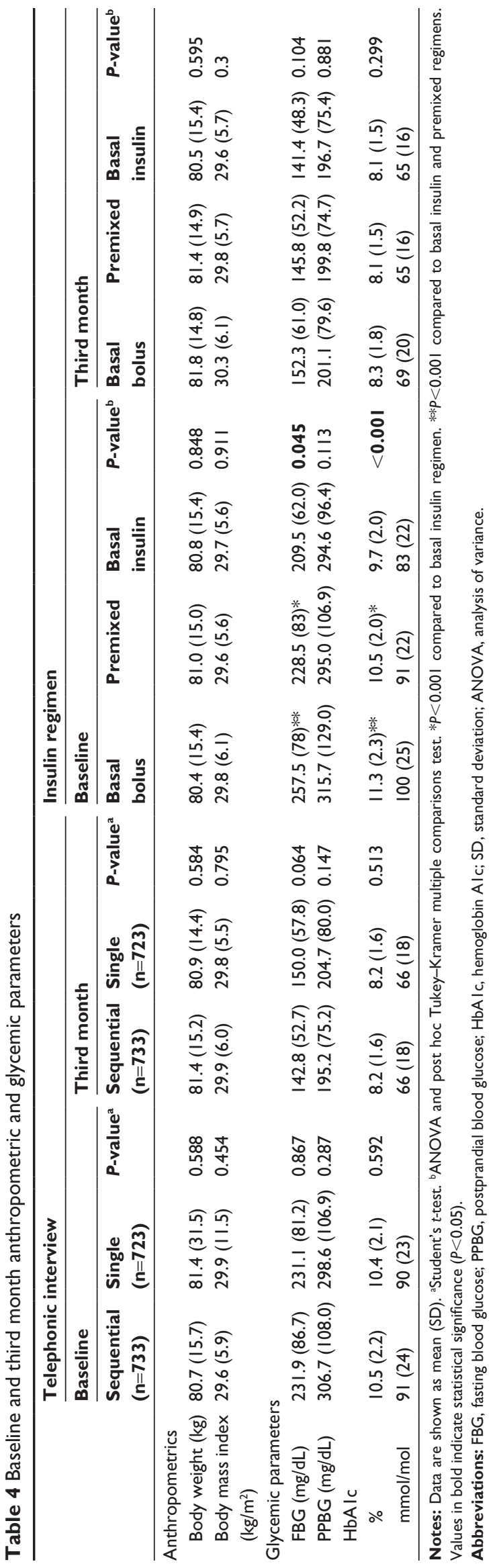

persistence, whereas negative appraisal of insulin therapy prior to treatment initiation (OR, 0.520 ; $95 \%$ CI, $0.363-0.746$; $P<0.001)$ was associated with lesser likelihood of persistence. Age, sex, and type of insulin regimen were not among the significant predictors of higher persistence (Table 7).

Logistic regression analysis with skipping an injection as the dependent variable revealed that basal bolus regimen (OR, 1.583; 95\% CI, 1.011-2.479; $P=0.045$ ) and higher HbA1c levels (OR, 1.114; 95\% CI, 1.028-1.207; $P=0.008$ ) were associated with increased likelihood of skipping an injection. Age, sex, diabetes duration, initial concerns about insulin therapy, and frequency of telephonic interview were not among the significant predictors of higher persistence (Table 7).

\section{Discussion}

Our findings in a Turkish cohort of insulin-naïve patients with type 2 diabetes initiated on different insulin regimens at tertiary health-care centers revealed a dropout rate of $15.5 \%$ and skipping an insulin dose in $21.2 \%$ of patients, leading to an overall nonadherence rate of $36.7 \%$ within 3 months.

Poor patient adherence in insulin therapy has also been consistently reported worldwide, ranging from $19.9 \%$ in France to $42 \%$ in the USA and $44 \%$ in Japan. ${ }^{6-9}$ According to multinational GAPP survey, among participating countries, insulin omission/nonadherence was reported to be highest in Turkey, followed by the USA, the People's Republic of China, and Japan, and lowest in France, Germany, UK, and Spain. ${ }^{4,7}$ One in three insulin-naïve patients initiating insulin have been indicated to never become ongoing users, ${ }^{10}$ with missing an injection in almost $60 \%$ of patients and missing doses on a regular basis in $20 \%{ }^{11}$ and $16 \%-49 \%$ of persistence reported at 6-12 months. ${ }^{12,13}$

Our previous findings in a cohort of 433 patients with insulin-naïve type 2 diabetes initiated on insulin therapy revealed poor persistence to insulin therapy, particularly in patients under basal bolus regimen, while negative perceptions about insulin therapy seemed to be the main cause for poor adherence. ${ }^{14}$

Similarly, having less negative appraisal of insulin therapy was among the significant determinants of higher persistence in our cohort. This seems in agreement with the suggestion of increased likelihood of treatment acceptance in the case of having less negative appraisal of insulin treatment than having more objections against this treatment option. ${ }^{15}$ Hence, identification of negative appraisal of insulin therapy in one-third of patients prior to treatment initiation seems notable. 
Table 5 Hypoglycemia with respect to insulin regimen and follow-up type

\begin{tabular}{|c|c|c|c|c|c|c|}
\hline & \multicolumn{6}{|c|}{ Hypoglycemia } \\
\hline & $\mathbf{N}$ & n (\%) & \multicolumn{4}{|c|}{$P$-value } \\
\hline \multicolumn{7}{|l|}{ Telephonic interview } \\
\hline Sequential interview & 528 & $125(23.6)$ & \multicolumn{4}{|l|}{0.08} \\
\hline Single interview & 489 & $139(28.4)$ & & & & \\
\hline \multirow[t]{3}{*}{ Total } & 1,017 & $264(26.0)$ & & & & \\
\hline & & & \multicolumn{2}{|c|}{ Sequential interview } & \multicolumn{2}{|c|}{ Single interview } \\
\hline & & & $\mathbf{N}$ & n (\%) & $\mathbf{N}$ & n (\%) \\
\hline \multicolumn{7}{|l|}{ Insulin regimen } \\
\hline Basal bolus & 262 & $80(30.5)$ & 148 & $43(29.1)$ & 114 & $37(32.5)$ \\
\hline Premixed & 435 & $148(34.0)$ & 202 & $58(28.7)$ & 233 & $90(38.6)$ \\
\hline Basal insulin & 320 & $36(11.2)^{*}$ & 178 & $24(13.5)$ & 142 & $12(8.5)^{*}$ \\
\hline Total & 1,017 & $264(26.0)$ & 528 & $125(12.2)$ & 489 & $139(13.7)$ \\
\hline
\end{tabular}

Notes: Chi-square test. $* P<0.0001$ compared to basal bolus and premixed insulin regimens.

In this regard, better persistence rates in our patients who had sequential rather than single telephonic interview during their follow-up, despite no interference in treatment during interviews, seems to indicate the help of effectively continued communication in overcoming negative appraisal of treatment and thus achievement of better compliance with the insulin regimens. Additionally, implementation of follow-up via telephonic interviews made by physicians who initiated the insulin regimen rather than through a nonspecific record system might also have a role in the better patient compliance.

Factors related to injection, complexity of the regimen, and more frequent and inflexible dosing schedules have been considered to be the key treatment-related barriers to insulin therapy. ${ }^{13,16-18}$ Similarly, major concerns about the insulin treatment were about the painful injections, risk of becoming insulin dependent, and risk of hypoglycemia and weight gain in our patients prior to treatment initiation. However, after treatment initiation, injections were reported to be painless by most of the patients. In addition, prior to treatment, $85.1 \%$ of our patients considered insulin to be an effective agent in blood glucose lowering, while normalization of blood glucose levels rather than injection-related problems become the main reason for treatment withdrawal at patients' discretion in our cohort.

Hence, our findings support that use of insulin pens may overcome some of the patient-related challenges including stigma and fear of initiation of insulin therapy $y^{1,19,20}$ and

Table 6 Patients' view on insulin therapy before and after treatment initiation

\begin{tabular}{|c|c|c|c|c|}
\hline \multicolumn{5}{|l|}{ Before treatment } \\
\hline \multicolumn{5}{|l|}{ General view } \\
\hline Positive appraisal & \multicolumn{4}{|l|}{$696(47.8)$} \\
\hline Negative appraisal & \multicolumn{4}{|l|}{$424(29.1)$} \\
\hline Neutral & \multicolumn{4}{|l|}{$159(10.9)$} \\
\hline Total & \multicolumn{4}{|l|}{$\mathrm{I}, 279(87.9)$} \\
\hline \multirow[t]{2}{*}{ Missing } & \multicolumn{4}{|l|}{176} \\
\hline & Yes & No & Total & Missing \\
\hline \multicolumn{5}{|l|}{ Insulin treatment is associated with } \\
\hline Normalization of blood glucose & $\mathrm{I}, 238(85.1)$ & $89(6.1)$ & I,327 (9I.2) & 128 \\
\hline Weight gain & $321(22.1)$ & $904(62.1)$ & $\mathrm{I}, 225(84.2)$ & 230 \\
\hline Hypoglycemia & $364(25.0)$ & $902(62.0)$ & $1,266(87.0)$ & 189 \\
\hline Painful injections & $534(36.7)$ & $800(55.0)$ & I,334 (91.7) & 121 \\
\hline Dependency & $47 \mathrm{I}(32.4)$ & $819(56.3)$ & $\mathrm{I}, 290(88.7)$ & 165 \\
\hline \multicolumn{5}{|l|}{ At the third month of treatment } \\
\hline \multicolumn{5}{|l|}{ Insulin treatment is associated with } \\
\hline Self-injection & $818(56.2)$ & $134(9.2)$ & $952(65.4)$ & 503 \\
\hline Painful injections & $89(6.1)$ & $860(59.1)$ & $949(65.2)$ & 506 \\
\hline Itching at the injection site & $32(2.2)$ & $918(63.1)$ & $950(65.3)$ & 505 \\
\hline Hives/swelling at the injection site & $18(1.2)$ & $930(63.9)$ & $948(65.2)$ & 507 \\
\hline
\end{tabular}

Note: Data are expressed as $n(\%)$. 
Table 7 Age-adjusted logistic regression analysis for factors predicting persistence and skipping an injection

\begin{tabular}{|c|c|c|c|c|c|c|c|c|}
\hline & \multicolumn{8}{|c|}{ Dependent variable } \\
\hline & \multicolumn{4}{|c|}{ Persistence } & \multicolumn{4}{|c|}{ Skipping doses } \\
\hline & \multirow[t]{2}{*}{$P$-value } & \multirow[t]{2}{*}{ OR } & \multicolumn{2}{|c|}{$95 \% \mathrm{Cl}$} & \multirow[t]{2}{*}{$P$-value } & \multirow[t]{2}{*}{ OR } & \multicolumn{2}{|c|}{$95 \% \mathrm{Cl}$} \\
\hline & & & Min & Max & & & Min & Max \\
\hline \multicolumn{9}{|l|}{ Insulin regimen } \\
\hline Basal bolus & 0.311 & 1.270 & 0.800 & 2.017 & 0.045 & 1.583 & 1.011 & 2.479 \\
\hline Premixed & 0.105 & 1.378 & 0.935 & 2.030 & 0.675 & 0.915 & 0.603 & 1.388 \\
\hline Basal insulin & Reference & & & & Reference & & & \\
\hline Age & 0.853 & 0.999 & 0.984 & 1.013 & 0.573 & 0.996 & 0.981 & 1.011 \\
\hline Diabetes duration & 0.001 & 1.063 & 1.026 & 1.102 & 0.537 & 0.990 & 0.959 & 1.022 \\
\hline \multicolumn{9}{|l|}{ Sex } \\
\hline Female & 0.724 & 0.941 & 0.670 & 1.321 & 0.206 & 0.804 & 0.573 & 1.127 \\
\hline Male & Reference & & & & Reference & & & \\
\hline \multicolumn{9}{|l|}{ Initial view } \\
\hline Negative & $<0.001$ & 0.520 & 0.363 & 0.746 & 0.890 & 1.027 & 0.709 & 1.487 \\
\hline Neutral & 0.422 & 0.804 & $0.47 I$ & $1.37 \mid$ & 0.923 & 0.975 & 0.584 & 1.627 \\
\hline Positive & Reference & & & & Reference & & & \\
\hline \multicolumn{9}{|l|}{ Telephonic interview } \\
\hline Sequential interview & 0.013 & 1.531 & 1.093 & 2.143 & 0.050 & 0.750 & 0.521 & 1.063 \\
\hline Single interview & Reference & & & & Reference & & & \\
\hline $\mathrm{HbAlc}$ & 0.049 & 1.090 & 0.999 & 1.189 & 0.008 & 1.114 & 1.028 & 1.207 \\
\hline Constant & 0.783 & 1.213 & & & 0.001 & 0.125 & & \\
\hline
\end{tabular}

Note: Values in bold indicate statistical significance $(P<0.05)$.

Abbreviations: OR, odds ratio; $\mathrm{Cl}$, confidence interval; Min, minimum; Max, maximum; HbAlc, hemoglobin Alc.

strongly suggest the temporality rather than stability of barriers to insulin therapy with likely modifications in the initial negative appraisal after the initiation of insulin therapy. ${ }^{15}$ Similarly, 3-month follow-up data on diabetes patients revealed increase in barriers to insulin therapy in patients kept on an oral regimen, whereas less negative appraisal of insulin treatment was reported in patients switched to insulin therapy. ${ }^{15}$

In this regard, sequential (via four repeated follow-up interviews on days $15,30,60$, and 90) rather than single (at day 90) telephonic interview seems to offer an option to enhance the flexibility of therapy, a better patient adherence, and ultimately, improved patient outcomes. ${ }^{21,22}$

Initiation of premixed or basal insulin regimens was associated with improved glycemic control in our patients with reduction in $\mathrm{HbA} 1 \mathrm{c}$ levels (from baseline levels of $10.5 \%$ [2.0\%] in premixed and 9.7\% [2.0\%] in basal insulin regimens to $8.1 \%$ [1.5\%] at 3 months for both) without causing weight gain within the course of 3 months. This seems consistent with data from treat-to-target studies concerning efficacy of insulin regimens $s^{1,23,24}$ as well as the similar efficacy reported for basal insulin and premixed insulin in lowering $\mathrm{HbA1c}$, while a lower rate of hypoglycemia with basal insulin in the literature. ${ }^{25}$

Data from a meta-analysis including 38,803 patients from 87 randomized clinical trials revealed a very strong positive relationship between baseline $\mathrm{HbAlc}$ and the magnitude of HbA1c change. ${ }^{26}$ However, both baseline (mean 11.3\%) and third month (mean 8.5\%) HbA1c levels were significantly higher in insulin-naïve patients initiating basal bolus rather than initiating other regimens in our cohort. Besides, our findings revealed high $\mathrm{HbA} 1 \mathrm{c}$ levels to be a significant predictor of both increased persistence and increased likelihood of skipping doses during 12 weeks, which may also be associated with identification of basal bolus regimen as significant predictor of higher likelihood of skipping doses in our cohort.

Given that anxiety and/or fear related to hypoglycemia in both patients and physicians can interfere with glycemic control, ${ }^{1}$ higher rates for hypoglycemia observed with use of basal bolus than other insulin regimens also seems be associated with consequent poor glycemic control, despite use of higher insulin doses and the increased likelihood of skipping doses in patients initiating basal bolus regimen.

Notably, in GAPP survey, it was suggested based on patient and physician statements that an ideal regimen would minimize the number of injections required, the risk of hypoglycemia, and the consequences of a delayed or missed insulin dose. ${ }^{4}$ Hence, while selected in younger patients with lesser diabetic complications in our cohort, initiating basal bolus regimen seems not to be an optimal therapeutic option in insulin-naïve patients with initially higher baseline HbA1c values. 
Indeed, given that sequential rather than single telephone interviews during follow-up were associated with higher persistence rates, and premixed and basal insulin regimens rather than basal bolus regimen were associated with lower rate of skipping an injection, follow-up of patients initiating basal bolus regimen based on single telephonic interview seems to be the least advantageous approach in the clinical care of insulin-naïve type 2 diabetes patients in terms of treatment adherence.

In addition, it should be noted that, in line with consideration of basal bolus regimen to be challenging for patients and physician due to complexity of implementation leading its underuse in patients with type 2 diabetes, ${ }^{27}$ basal bolus regimen was the least commonly initiated (27.5\%) insulin regimen in our cohort.

Improved glycemic control has been indicated to be judged only in the context of hypoglycemia incidence and insulin dose. ${ }^{28}$ In this regard, basal insulin, as the regimen associated with lowest insulin doses and lowest rates of minor or major hypoglycemia along with lower rate of skipping an injection in our cohort, seems to offer a good alternative in insulin initiators. Indeed, higher rate of concomitant metformin treatment was noted in our patients initiating basal insulin than initiating other insulin regimens. This seems in accordance with the consideration of basal insulin plus oral antidiabetes drugs as a well-validated option to enhance insulin initiation, ${ }^{29}$ while additional use of metformin may also have resulted in further improvement in glycemic control in these patients. ${ }^{28}$

Notably, unlike the single interview of patients on basal bolus and basal insulin regimens, which revealed lower persistence rates compared with sequential interview, persistence rates were similar between single and sequential interview groups of patients initiating premixed regimen. Moreover, single interview revealed significantly higher persistence for patients initiating premixed than basal insulin regimen.

Use of insulin pen has been associated with lower rates of hypoglycemia, greater adherence and persistence, and thereby greater glycemic control. ${ }^{1}$ In this regard, while all patients were on insulin pen therapy, identification of nonadherence in more than one-third of our cohort of patients with type 2 diabetes emphasizes further investigation of determinants of nonadherence to insulin therapy among Turkish patients with type 2 diabetes given the consequent poor clinical outcome. ${ }^{3,5,6}$

Indeed, given that treatment discontinuation was based on physician decision in $25.0 \%$ of discontinuers, the role of physician-related factors in insulin adherence should also be emphasized. Since a lack of consensus among national guidelines and recommendations may induce the clinical inertia observed among clinicians, ${ }^{23,30,31}$ consideration of the guidelines within the context of a patient-centered approach by individualizing insulin therapy to a regimen that is compatible with the patient's glucose profile, as well as with the current information on evolving new insulin formulations, seems to be the best possible modality to overcome challenges to achieving glycemic control. ${ }^{1,32}$

The major strength of this open-label randomized multicenter study seems to be the inclusion of data on 1,456 insulin-naïve patients with type 2 diabetes at 13 centers in Turkey, which enables our findings likely to be generalizable based on the presence of a representative sample of the overall population. However, certain limitations to this study should be considered. First, our findings are based on self-reported medication adherence, which could be biased by patients' foreknowledge of their laboratory results. Lack of data on adherence to other aspects of the diabetes treatment such as diet and physical activity seems to be another limitation, which otherwise would extend the knowledge achieved in the current study. Nevertheless, despite these certain limitations, given the paucity of solid information available in this area, our findings represent a valuable contribution to the literature.

\section{Conclusion}

Our findings in a Turkish cohort of insulin-naïve patients with type 2 diabetes initiated on different insulin regimens revealed low adherence to insulin treatment in terms of drop out as well as skipping doses in a 3-month follow-up. Our findings indicate higher likelihood of persistence in the case of sequential rather than single telephonic interview with patients, higher likelihood of skipping an injection in the case of initiating basal bolus rather than other insulin regimens and increased rates for persistence while also skipping an injection in the case of poor glycemic control.

\section{Acknowledgments}

The members of the Dropout Study Group are listed below: Dilek GogasYavuz, MD, Faculty of Medicine, Marmara University, Istanbul, Turkey; Habip Bilen, MD, Faculty of Medicine, Ataturk University, Erzurum, Turkey; Seda Sancak, MD, Fatih Sultan Mehmet Training and Research Hospital, Istanbul, Turkey; Tayfun Garip, MD, and Dilek Arpaci, MD, Sakarya State Hospital, Sakarya, Turkey; Zeliha Hekimsoy, MD, Faculty of Medicine, Celal Bayar University, Manisa, Turkey; Ibrahim Sahin, MD, Faculty of Medicine, Inonu University, Malatya, Turkey; Murat Yilmaz, MD, 
Faculty of Medicine, Namık Kemal University, Tekirdag, Turkey; Hasan Aydin, MD, Faculty of Medicine, Yeditepe University, Istanbul, Turkey; Aysegul Atmaca, MD, Faculty of Medicine, Ondokuzmayis University, Samsun, Turkey; Murat Sert, MD, Faculty of Medicine, Cukurova University, Adana, Turkey; Pinar Karakaya, Bakirkoy Training and Research Hospital, Istanbul, Turkey; Aytekin Oguz, MD, Faculty of Medicine, Medeniyet University, Istanbul, Turkey; Nilgun Guvener, Faculty of Medicine, Baskent University, Istanbul, Turkey; Serpil Esmen, RN, Faculty of Medicine, Marmara University, Istanbul, Turkey; Sevin Dakak, RN, Faculty of Medicine, Ataturk University, Erzurum, Turkey; Behice Kahraman, RN, Fatih Sultan Mehmet Training and Research Hospital, Istanbul, Turkey; Betül Beyaz, RN, Sakarya State Hospital, Sakarya, Turkey; Sinem Yaman, RN, Faculty of Medicine, Namık Kemal University, Tekirdag, Turkey; Deniz Sarı, RN, Faculty of Medicine, CelalBayar University, Manisa, Turkey; Sibel Günışık, RN, Faculty of Medicine, Inonu University, Malatya, Turkey; Betül Demir, RN, Faculty of Medicine, Yeditepe University, Istanbul, Turkey; Gülay Bayrak, RN, Faculty of Medicine, Ondokuzmayıs University, Samsun, Turkey; Ayfer Bahtiyar, RN, Faculty of Medicine, Cukurova University, Adana, Turkey; Neşe Işık, RN, Bakirkoy Training and Research Hospital, Istanbul, Turkey; Nurdan Yörük, RN, Faculty of Medicine, Medeniyet University, Istanbul, Turkey; and Emel Nur Ulusoy, RN, Faculty of Medicine, Baskent University, Istanbul, Turkey.

\section{Disclosure}

The authors report no conflicts of interest in this work.

\section{References}

1. Sorli C, Heile MK. Identifying and meeting the challenges of insulin therapy in type 2 diabetes. J Multidiscip Healthc. 2014;7:267-282.

2. Wright A, Burden AC, Paisey RB, Cull CA, Holman RR; U.K. Prospective Diabetes Study Group. Sulfonylurea inadequacy: efficacy of addition of insulin over 6 years in patients with type 2 diabetes in the UK Prospective Diabetes Study (UKPDS 57). Diabetes Care. 2002; 25(2):330-336.

3. Del Prato S, Penno G, Miccoli R. Changing the treatment paradigm for type 2 diabetes. Diabetes Care. 2009;32(suppl 2):217-222.

4. Peyrot M, Barnett AH, Meneghini LF, Schumm-Draeger PM. Insulin adherence behaviours and barriers in the multinational Global Attitudes of Patients and Physicians in Insulin Therapy study. Diabet Med. 2012;29(5):682-689.

5. Morris AD, Boyle DI, McMahon AD, Greene SA, MacDonald TM, Newton RW. Adherence to insulin treatment, glycaemic control, and ketoacidosis in insulin-dependent diabetes mellitus. The DARTS/ MEMO Collaboration. Diabetes Audit and Research in Tayside Scotland. Medicines Monitoring Unit. Lancet. 1997;350(9090):1505-1510.

6. Aronson R. The role of comfort and discomfort in insulin therapy. Diabetes Technol Ther. 2012;14(8):741-747.
7. Pharmafile [webpage on the Internet]. Treatment Flexibility Will Improve Adherence in Diabetes, Study Suggests. Findings from Global Attitudes of Patients and Physicians in Insulin Therapy Study. Available from: http://www.pharmafile.com/news/161079/treatmentflexibility-will-improve-adherence-diabetes-study-suggests. Accessed April 7, 2015.

8. Spann SJ, Nutting PA, Galliher JM, et al. Management of type 2 diabetes in the primary care setting: a practice-based research network study. Ann Fam Med. 2006;4(1):23-31.

9. Barnett AH, Meneghini LF, Schumm-Draeger P-M, Peyrot M. The GAPP (Global Attitudes of Patients and Physicians in Insulin Therapy) study: identifying risk factors associated with injection omission/nonadherence in insulin treated patients with type 1 and type 2 diabetes. Diabet Med. 2012;29(suppl 1):168.

10. Karter AJ, Subramanian U, Saha C, et al. Barriers to insulin initiation: the translating research into action for diabetes insulin starts project. Diabetes Care. 2010;33(4):733-735.

11. Peyrot M, Rubin RR, Kruger DF, Travis LB. Correlates of insulin injection omission. Diabetes Care. 2010;33(2):240-245.

12. Dailey G, Kim MS, Lian JF. Patient compliance and persistence with antihyperglycemic drug regimens: evaluation of a medicaid patient population with type 2 diabetes mellitus. Clin Ther. 2001; 23(8):1311-1320.

13. Bonafede MM, Kalsekar A, Pawaskar M, et al. A retrospective database analysis of insulin use patterns in insulin-naïve patients with type 2 diabetes initiating basal insulin or mixtures. Patient Prefer Adherence. 2010;4:147-156.

14. Yavuz DG, Ozcan S, Deyneli O. Adherence to insulin treatment in insulin-naive type 2 diabetic patients initiated on different insulin regimens. Patient Prefer Adherence. 2015;9:1225-1231.

15. Hermanns N, Mahr M, Kulzer B, Skovlund SE, Haak T. Barriers towards insulin therapy in type 2 diabetic patients: results of an observational longitudinal study. Health Qual Life Outcomes. 2010;8:113.

16. Cramer JA. A systematic review of adherence with medications for diabetes. Diabetes Care. 2004;27(5):1218-1224.

17. Oliveria SA, Menditto LA, Ulcickas Yood M, Koo YH, Wells KE, McCarthy BD. Barriers to the initiation of, and persistence with, insulin therapy. Curr Med Res Opin. 2007;23(12):3105-3112.

18. Odegard PS, Capoccia K. Medication taking and diabetes: a systematic review of the literature. Diabetes Educ. 2007;33(6):1014-1029. Discussion 1030-1031.

19. Korytkowski M, Bell D, Jacobsen C, Suwannasari R; FlexPen Study Team. A multicenter, randomized, open-label, comparative, two-period crossover trial of preference, efficacy, and safety profiles of a prefilled, disposable pen and conventional vial/syringe for insulin injection in patients with type 1 or 2 diabetes mellitus. Clin Ther. 2003;25(11): 2836-2848.

20. Flood T. Advances in insulin delivery systems and devices: beyond the vial and syringe. Insulin. 2006;1:99-108.

21. Benroubi M. Fear, guilt feelings and misconceptions: barriers to effective insulin treatment in type 2 diabetes. Diabetes Res Clin Pract. 2011; 93(suppl 1):S97-S99.

22. Petznick AM. Identifying and addressing barriers to insulin acceptance and adherence in patients with type 2 diabetes mellitus. $J$ Am Osteopath Assoc. 2013;113(4 suppl 2):S6-S16.

23. American Diabetes Association. Standards of medical care in diabetes - 2014. Diabetes Care. 2014;37(suppl 1):S14-S80.

24. el-Kebbi IM, Ziemer DC, Gallina DL, Dunbar V, Phillips LS. Diabetes in urban African-Americans. XV. Identification of barriers to provider adherence to management protocols. Diabetes Care. 1999; 22:1617-1620.

25. Freemantle N, Balkau B, Home PD. A propensity score matched comparison of different insulin regimens 1 year after beginning insulin in people with type 2 diabetes. Diabetes Obes Metab. 2013; 15(12):1120-1127. 
26. Giugliano D, Maiorino M, Bellastella G, Chiodini P, Esposito K. Relationship of baseline $\mathrm{HbA1c}, \mathrm{HbA} 1 \mathrm{c}$ change and $\mathrm{HbA} 1 \mathrm{c}$ target of $<7 \%$ with insulin analogues in type 2 diabetes: a meta-analysis of randomized controlled trials. Int J Clin Pract. 2011;65(5):602-612.

27. Ratner R, Wynne A, Nakhle S, Brusco O, Vlajnic A, Rendell M. Influence of preprandial vs postprandial insulin glulisine on weight and glycaemic control in patients initiating basal-bolus regimen for type 2 diabetes: a multicenter, randomized, parallel, open-label study (NCT00135096). Diabetes Obes Metab. 2011;13(12):1142-1148.

28. Gordon J, Pockett RD, Tetlow AP, McEwan P, Home PD. A comparison of intermediate and long-acting insulins in people with type 2 diabetes starting insulin: an observational database study. Int J Clin Pract. 2010; 64(12):1609-1618.

29. Vergès B, Brun JM, Tawil C, Alexandre B, Kerlan V. Strategies for insulin initiation: insights from the French LIGHT observational study. Diabetes Metab Res Rev. 2012;28(1):97-105.
30. Rodbard HW, Jellinger PS, Davidson JA, et al. Statement by an American Association of Clinical Endocrinologists/American College of Endocrinology consensus panel on type 2 diabetes mellitus: an algorithm for glycemic control. Endocr Pract. 2009;15(6):540-549.

31. LaSalle JR. Empowering patients during insulin initiation: a real-world approach. J Am Osteopath Assoc. 2010;110(2):69-78.

32. Inzucchi SE, Bergenstal RM, Buse JB, et al; American Diabetes Association (ADA), European Association for the Study of Diabetes (EASD). Management of hyperglycemia in type 2 diabetes: a patientcentered approach: position statement of the American Diabetes Association (ADA) and the European Association for the Study of Diabetes (EASD). Diabetes Care. 2012;35:1364-1379.

\section{Publish your work in this journal}

Patient Preference and Adherence is an international, peer-reviewed, open access journal that focuses on the growing importance of patient preference and adherence throughout the therapeutic continuum. Patient satisfaction, acceptability, quality of life, compliance, persistence and their role in developing new therapeutic modalities and compounds to optimize clinical outcomes for existing disease states are major areas of interest for the journal. This journal has been accepted for indexing on PubMed Central. The manuscript management system is completely online and includes a very quick and fair peer-review system, which is all easy to use. Visit http://www. dovepress.com/testimonials.php to read real quotes from published authors.

\footnotetext{
Submit your manuscript here: http://www.dovepress.com/patient-preference-and-adherence-journal
} 